\title{
REFORMA EDUCACIONAL, INTENSIFICAÇÃO E AUTOINTENSIFICAÇÃO DO TRABALHO DOCENTE
}

\author{
Maria Manuela Alves Garcia* \\ Simone BarReto ANADON ${ }^{* *}$
}

\begin{abstract}
RESUMO: O estudo problematiza um conjunto de oito depoimentos de natureza biográfica de professoras de séries iniciais da rede de ensino municipal do Capão do Leão, Rio Grande do Sul, Brasil, estabelecendo um diálogo com as categorias de governamentalidade, intensificação do trabalho docente, cuidado e gênero, a fim de contribuir para o entendimento das mudanças que vêm atingindo o trabalho docente nas séries iniciais, no bojo das políticas de reforma educacional das décadas finais do século XX, no Brasil. A precarização das condições de trabalho dos professores da educação básica, os baixos salários do magistério, as novas demandas de trabalho na gestão da escola, dos currículos e do ensino, as políticas oficiais de profissionalização, o estímulo a uma moral de autorresponsabilização e culpa por parte do discurso oficial, que toma como objeto de governo a subjetividade das professoras e as emoções no ensino, têm como efeitos a intensificação e a autointensificação do trabalho docente.
\end{abstract}

Palavras-chave: Reforma educacional. Trabalho docente. Intensificação. Autointensificação.

\section{EDUCATIONAL REFORM, INTENSIFICATION OF TEACHER'S WORK AND SELF-EXPLOITATION}

ABSTRACT: This study problematizes eight biographical accounts of public elementary school teachers in Capão do Leão, a small town in Rio Grande do Sul, Brazil. It strives to contribute to understand

* Doutora em Educação e professora do Curso de Pós-Graduação em Educação (PPGE), da Universidade Federal de Pelotas (UfPeL).E-mail: garciamariamanuela@gmail.com

** Mestre em Educação e professora da Fundação Universitária do Rio Grande (FURG) E-mail: simoanadon@hotmail.com

Educ. Soc., Campinas, vol. 30, n. 106, p. 63-85, jan./abr. 2009 
better the transformations in teachers' work embedded in the late $20^{\text {th }}$ century educational reform policies by establishing a dialogue among the following analytical categories: governmentality, intensification of teachers' work, care and gender. The intensification of teachers' work and self-exploitation is driven by: the precarious working conditions of elementary school teachers; low salaries; new administrative, curricular and instructional demands; official policies for teacher "professionalization"; and an official discourse that promotes norms of individual responsibility and guilt and aims to govern the subjectivity and emotions of teachers.

Key words: Educational reform. Teachers' work. Intensification. Selfexploitation.

7 s mudanças no trabalho escolar e docente, que vêm acontecendo no bojo das reformas educacionais instituídas no Brasil a partir da última década do século Xx, têm sido objeto de estudo de uma literatura que busca compreender os impactos das políticas educacionais oficiais nos currículos e no trabalho dos professores brasileiros. Estudos como os de Oliveira (2004), Sampaio e Marin (2004) têm destacado a precarização e flexibilização em curso no trabalho dos docentes brasileiros com a implantação de novos mecanismos de governo e controle do trabalho escolar e docente, sugerindo que esses processos ainda estão longe de ter esgotado nossos esforços de compreensão.

É nesse campo temático que este trabalho se insere. Tendo como categorias centrais os conceitos de governamentalidade, intensificação do trabalho docente, cuidado e gênero, e dialogando com uma série de estudos e pesquisas, traz-se para este texto um conjunto de depoimentos orais de oito professoras ${ }^{1}$ de $1^{\text {a }}$ a $4^{\text {a }}$ séries do magistério municipal do Capão do Leão/Rs, ${ }^{2}$ com idades entre 23 e 44 anos, a fim de exemplificar a natureza das mudanças que vêm ocorrendo no trabalho das professoras nesse nível de ensino. São depoimentos de natureza biográfica, coletados para pesquisa (Anadon, 2005) que investigou as representaçôes do magistério de $1^{\mathrm{a}}$ a $4^{\mathrm{a}}$ série sobre os impactos das reformas educacionais dos anos de 1990 no trabalho escolar e na identidade profissional do magistério desse segmento do ensino básico. Retomamos aqui esses depoimentos para sugerir algumas hipóteses sobre os modos como as políticas educacionais oficiais vêm 
contribuindo para a precarização e intensificação do trabalho docente nas últimas décadas no Brasil.

Quer-se demonstrar que as políticas educacionais para a educação básica no Brasil, desde a década de 1990, vêm introduzindo formas de controle e intensificação do trabalho docente que tomam como objeto de governo a subjetividade das professoras e as emoções no ensino (Hargreaves, 1998). Elas estimulam uma moral de autorresponsabilização e culpa por parte das professoras, que, aliada à deterioração dos salários e das condições de trabalho, vem contribuindo para a intensificação e autointensificação do trabalho docente e para a geração de frustraçôes e desencantos.

O fato de a categoria docente do ensino básico ser predominantemente feminina influencia os modos como as professoras têm seu trabalho intensificado, as suas formas de resistência, os sentidos que atribuem ao que fazem e como lidam com as demandas das políticas educacionais oficiais nos contextos em que trabalham. A natureza dos cuidados que historicamente tem caracterizado a educação elementar da infância, que vai muito além de uma educação meramente instrumental, faz parte das autoimagens de docência das professoras deste estudo, aspecto que tem sido estrategicamente utilizado pela retórica oficial de modo a estimular a responsabilização das docentes pelos resultados e pelas condições em que desenvolvem o seu trabalho.

$\mathrm{O}$ entendimento das reformas educacionais como dispositivos de recomposição dos mecanismos de regulação social no interior dos aparatos educacionais e escolares, e de instituição de novas racionalidades de governo dos diferentes agentes educacionais, como os professores, é o horizonte conceitual da análise dos depoimentos das professoras. As políticas educacionais das últimas décadas dos anos de 1990 são entendidas como discursos e dispositivos de uma governamentalidade neoliberal, que fornecem uma série de ordenamentos para a organização dos currículos e do ensino e criam um campo de possibilidades para a ação dos professores e de outros agentes educacionais. O governo da alma e da subjetividade humana tornouse, no interior dessa racionalidade, uma estratégia indispensável das modernas formas de administração e (auto)gestão das pessoas no mundo contemporâneo (Peters, Marshall \& Fitzsimons, 2004; Rose, 1996). 
São aspectos desses depoimentos, que destacam as formas de (auto)intensificação do trabalho escolar e docente e os modos de exploração das emoções no ensino, que se busca problematizar a seguir. Mas antes é preciso caracterizar as reformas educacionais aqui em foco.

As reformas educacionais dos anos de 1990 e as mudanças no trabalho escolar e docente

Os estudos que se dedicam a discutir as reformas educacionais são unânimes em vincular as transformações em curso no campo educacional e no trabalho docente à emergência no pós-guerra de uma nova ordem econômica internacional que, sob o impacto da revolução científica e tecnológica advinda da microeletrônica, vem alterando profundamente os processos econômicos e as relações de trabalho, mas também o campo da cultura e os modos de existência e subjetividade dos indivíduos e grupos sociais. Sob o ideário neoliberal e das diretrizes ditadas por organismos financeiros internacionais, as reformas e as políticas educacionais oficiais, desde a última década do século xx no Brasil, combinaram formas de planejamento e controle central na formulação das políticas e descentralização administrativa e financeira na sua implementação, possibilitando uma série de novas parcerias na gestão pedagógica e administrativa da escola, as quais tiveram de ser construídas ativamente também pelo governo das subjetividades.

O movimento de empresariamento do Estado e da alma humana faz-se acompanhar de uma ética e de uma linguagem baseadas no mercado e na performatividade, impondo novas categorias e termos para pensar o mundo, a sociedade e os indivíduos. A defesa da educação como direito social e bem público vem se tornando rapidamente no imaginário social algo ultrapassado e inalcançável diante da crise fiscal e da derrocada de soberania dos Estados contemporâneos.

É verdade que em países pobres ou ditos em desenvolvimento, como o Brasil, as racionalidades neoliberais na esfera educacional são objeto de intensas contestaçôes, tendo os governos que recuar diante das dificuldades e dos embates que essas medidas na maioria das vezes suscitam, seja pelo ativismo de esquerda da comunidade científica e dos sindicatos de professores e/ou seja pelas dificuldades que essas políticas enfrentam no momento de serem recontextualizadas no interior 
das instituições educacionais. No entanto, novos mecanismos de regulação e gestão têm sido efetivamente implantados pelas reformas das últimas décadas do século XX no Brasil.

Entre os aspectos e as mudanças que apontam para a precarização do trabalho dos professores podem-se destacar a desqualificação da formação profissional dos docentes pela pedagogia oficial das competências, a intensificação do trabalho dos professores em decorrência do alargamento das funções no trabalho escolar e das jornadas de trabalho, os baixos salários docentes que não recompuseram as perdas significativas que sofreram nos anos da ditadura militar. Também a padronização dos currículos do ensino básico e da formação docente e a instituição de exames nacionais favoreceram a emergência de novas estratégias de controle, baseadas na auditoria, no desempenho e no recrudescimento da culpa e da autorresponsabilização docentes. Essas estratégias estão deslocando, em parte, formas de controle do trabalho docente que predominaram na organização curricular da década de 1970, baseadas na vigilância e supervisão direta dos professores pelos chamados especialistas da educação e na demanda intensa de trabalho burocrático para prestação de contas do ensino.

A precarização do trabalho docente no ensino básico no Brasil não é um fenômeno recente. Os anos do regime militar (1964-1985), segundo diz Ferreira Jr. e Bittar (2006), coincidiram com três fenômenos associados, decorrentes da política econômica e educacional, e alteraram radicalmente a configuração de classe dos docentes desse nível de ensino: a rápida expansão numérica demandada pela obrigatoriedade da escola fundamental de oito anos instituída pela Lei n. 5.692/ 71 , a aceleração da formação docente proposta pela reforma universitária de 1968 e o arrocho salarial durante todo o período da ditadura. Condições essas que irão levar a categoria docente a uma proximidade política com a luta sindical dos demais trabalhadores.

Para ilustrar o violento arrocho salarial sofrido pela categoria docente, Ferreira Jr. e Bittar (2006, p. 1.169) apresentam o estudo desenvolvido por Cunha (1991), da evolução salarial dos professores do ensino básico nos estados de São Paulo e Rio de Janeiro: em 1967, os professores primários da rede estadual de São Paulo recebiam um salário médio por hora equivalente a 8,7 vezes o salário mínimo; em 1979, essa média já tinha baixado para 5,7 vezes. No Rio de Janeiro, com 
Reforma educacional, intensificação e autointensificação do trabalho docente

uma série de tempo mais longa, em 1950, os professores recebiam por hora 9,8 vezes o salário mínimo da época; em 1960, essa média já tinha baixado para 4 vezes; em 1977 , cai para 2,8 e, por último, em 1990, já estava em 2,2 salários mínimos.

Em seu estudo sobre a trajetória da Confederação dos Professores do Brasil ( $\mathrm{CPB})$, e analisando as classes sociais em que passaram a ser recrutados os professores do ensino básico, caracteriza esses anos como um período que significou a pauperização econômica e cultural que deixou para trás a década de 1950, quando ainda o professor desfrutava um status social e econômico reconhecido, selando seu destino político à luta sindical dos demais trabalhadores (Ferreira Jr. \& Bittar, 2006, p. 1.166).

$\mathrm{Na}$ passagem ao século XXI os salários docentes não tinham ainda recuperado as perdas sofridas nos regimes militares. Em 1997, o $1^{\circ}$ Censo do Professor do INEP mostrava que a média salarial nacional dos professores do ensino fundamental de $1^{\mathrm{a}}$ a $4^{\mathrm{a}}$ série variava entre $\mathrm{R} \$$ 147,34 , para os que tinham até o $1^{\circ}$ grau, e $\mathrm{R} \$ 687,61$, para aqueles que tinham o $3^{\circ}$ grau completo ou mais. Em 2003, o mesmo INEP, por meio da "Sinopse do Censo dos Professores do Magistério da Educação Básica", indicava que a média salarial dos professores brasileiros de $1^{\text {a }}$ a $4^{a}$ série variava entre $R \$ 300,00$, para aqueles que tinham o nível de escolaridade fundamental, até $\mathrm{R} \$ 644,00$, para aqueles com nível superior, curso de licenciatura, evidenciando que a média salarial dos professores não se tinha alterado significativamente, especialmente para aqueles com níveis de escolaridade mais altos.

Corroborando esses dados, pesquisa realizada pela UNESCO entre os meses de abril e maio de 2002, respondida por 5.000 docentes de escolas públicas e privadas do ensino fundamental e médio das 27 Unidades da Federação, mostrou que 73\% dos docentes atuantes na rede pública de ensino tinham uma renda familiar mensal entre 2 e 10 salários mínimos, sendo que as rendas mais baixas eram as dos professores que trabalhavam no interior, nas periferias e/ou residiam em municípios com menos de 5.000 habitantes (UNESCO, 2004). Também a Confederação Nacional dos Trabalhadores em Educação (CNTE) denunciava em 2003, no "Relatório de Pesquisa sobre a Situação dos Trabalhadores(as) da Educação Básica”, que de 1997 em diante não tinha havido praticamente crescimento dos salários dos professores 
brasileiros, sendo que a média salarial se situava na faixa de $R \$ 600,00$, estando o Brasil em pior posição que a Indonésia à época da pesquisa.

É a esse quadro geral de pobreza dos professores brasileiros que vem se somar o aumento das atribuiçôes trazidas pelos modelos de gestão escolar e curricular adotados pelas políticas de reforma dos anos de 1990. Em meio a discursos que desqualificavam e desautorizavam fortemente os professores, responsabilizando-os pelo fracasso e pela inadequação da escola pública, ampliaram-se também as exigências relativas à qualificação dos docentes, como a exigência de titulação em cursos de licenciatura e a inclusão em programas de formação continuada, impelindo-os a assumir novos papéis, como o de estudantes em cursos de habilitação profissional. ${ }^{3}$ Em contrapartida, essas mudanças não foram acompanhadas de melhorias na estrutura física escolar nem de melhorias nas condiçôes de trabalho ou nas carreiras docentes.

Às escolas em péssimas condiçōes físicas, às precárias condiçōes de trabalho e aos problemas sociais vivenciados pelos professores em suas escolas e salas de aula, vieram se somar novas tarefas, atividades e responsabilidades. Termos como cidadania, qualidade de ensino, compromisso social, doação, empenho, comprometimento docente e relação dialógica aparecem no interior dos discursos das políticas educacionais oficiais, interpelando as professoras em suas imagens e autoimagens docentes. As professoras deste estudo se sentem convocadas por discursos que mesclam um certo caráter missionário e humanitário da docência com argumentos relacionados ao profissionalismo e à profissionalização docente.

As novas exigências no processo de trabalho escolar e docente resultam na intensificação do trabalho pelo menos sob dois aspectos: a intensificação pela ampliação das demandas profissionais na vida das professoras, impelidas desde uma perspectiva administrativa e burocrática; e a autointensificação, pela exploração do sentimento de profissionalismo das professoras e de suas autoimagens calcadas no cuidado e no zelo que caracterizam historicamente a educação da infância.

A intensificação do trabalho docente e a colonização administrativa do tempo dos professores

A expressão "intensificação do trabalho docente" tem sido utilizada por Apple (1995) e Hargreaves (1998) no contexto de investigaçōes 
que tentam entender os processos de racionalização e controle do processo de trabalho do ensino, tendo como referência a organização do processo de trabalho capitalista e a administração científica do trabalho.

Diz Apple (1995) que a intensificação, em termos gerais, "representa uma das formas tangíveis pelas quais os privilégios de trabalho dos(as) trabalhadores(as) educacionais são degradados” (p. 39), caracterizando-se pela crescente demanda de novas atribuições, pela falta de tempo para as atividades mais básicas da vida humana e pelo sentimento de cansaço crônico dos trabalhadores intelectuais em função do excesso de trabalho. Apple (1995) descreve o fenômeno da intensificação do trabalho docente em seus estudos sobre os movimentos de reforma nos Estados Unidos, que buscaram a racionalização do trabalho escolar e docente por meio da implementação de objetivos comportamentais, de pacotes instrucionais e da cobrança burocrática do processo de ensino e aprendizagem. Nesse contexto, relacionou a intensificação do trabalho docente especialmente à colonização administrativa e burocrática do tempo de trabalho dos professores com a sobrecarga de tarefas e registros de prestação de contas do ensino e da aprendizagem, bem como ao movimento de proletarização da categoria docente.

Também Hargreaves (1998, p. 121) denuncia a "colonização" crescente do tempo de trabalho dos professores, sendo "o processo pelo qual os administradores absorvem ou 'colonizam' o tempo e os espaços dos professores com os seus próprios propósitos”, tratando de ocupar objetivamente o tempo dos docentes com tarefas e atribuiçôes demandadas pelas instâncias administrativas e relacionadas ao ensino e à gestão dos currículos e da escola, motivados por questôes relacionadas à produtividade e ao controle. Essas formas de colonização têm utilizado especialmente a vigilância direta e o controle burocrático dos professores a fim de garantir a efetiva utilização produtiva do tempo de trabalho.

Mas, o próprio Hargreaves (1998) destaca, para além dessas formas de colonização administrativa do tempo e do espaço dos professores em sala de aula, estão em curso nos últimos anos formas mais sofisticadas que tendem a incluir regiōes e atividades da vida profissional dos docentes "mais informais, carregadas de desejo" ou mesmo improdutivas e contraproducentes. Por exemplo, a programação administrativa dos 
tempos que os professores passam longe das salas de aula, como os intervalos para o cafezinho, ou a inclusão na jornada de trabalho escolar do tempo de preparação e planejamento de aulas.

Levando em conta as contribuições desses estudos, a intensificação do trabalho docente é entendida neste trabalho como o fenômeno da ampliação das responsabilidades e atribuiçôes no cotidiano escolar dos professores considerando o mesmo tempo de trabalho, indo além das tarefas instrucionais e pedagógicas, para abarcar as questôes de administração e gestão da escola e o desenvolvimento de atividades de formação que lhes proporcionem rever habilidades e competências necessárias para educar as novas geraçôes de acordo com as demandas do mercado. Mas quer-se argumentar, especificamente na seção a seguir deste texto, que a intensificação do trabalho docente nos tempos contemporâneos é também resultado de uma crescente colonização administrativa das subjetividades das professoras e das emoções no ensino, sendo indícios desse fenômeno a escalada de pressões, expectativas, culpas, frustrações, impelidas burocraticamente e/ou discursivamente, relativamente àquilo que as professoras são ou deveriam ser profissionalmente, àquilo que as professoras fazem ou deveriam fazer, seja no ambiente escolar ou mesmo fora da escola.

Nas entrevistas aqui analisadas, as professoras trazem à tona o quanto o seu trabalho tem sido intensificado nas últimas décadas seja pelo aumento das atribuições e/ou pelo aumento das jornadas de trabalho:

Nós saímos daqui, nós chegamos em casa é prova para corrigir, é trabalho para corrigir, é aula para preparar, é isso que eu estou dizendo! Nós não temos essa vantagem de sair daqui sem problemas! E isso aí o governo não vê! É isso que nós deveríamos ser valorizadas! Porque nós não trabalhamos só aqui 40 horas, nós trabalhamos em casa também! Então o professor que trabalha 60 ele tem que trabalhar 80 , porque ele vai ter que achar [risos] mais 20 horas para trabalhar dentro de casa! Aí ele não acha! Então ele faz um trabalho mecânico!

Irene, com 42 anos de idade e 22 anos de profissão, lembra que, no início de sua carreira, nos anos de 1980, poucas professoras trabalhavam mais do que 20 horas, mas ressalta que, diante do achatamento salarial que atingiu as categorias de professores do ensino público, foi necessário paulatinamente aumentar as jornadas de trabalho. 
Essa é uma observação difícil de comprovar estatisticamente. Segundo a pesquisa da UNESCO (2004), em 2002, 54,2\% dos professores do ensino básico cumpriam uma jornada semanal de 21 a 40 horas, $30,9 \%$ trabalhavam de 1 a 20 horas e um porcentual de 14,8\% dos professores trabalhavam mais de 40 horas semanais. Em contrapartida, mais da metade desses professores atuava em uma única escola (58,5\%), 32,2\% trabalhavam em duas escolas e 9,2\% em três ou mais escolas. Esses dados são também corroborados pela Sinopse Estatística de 2003 do INEP, que encontrou a maioria dos professores da educação básica trabalhando entre 11 e 40 horas semanais.

Em Além disso, o estudo da CNTE, mesmo afirmando que a grande maioria dos seus entrevistados é contratada por 40 horas semanais e exerce o seu trabalho em uma escola, constata que muitos deles dedicam em média 14 horas semanais a serviços extras remunerados e 8 horas de trabalho em casa dedicados à atividade profissional, resultando no acréscimo de 22 horas a uma jornada que pode variar de 20 a 40 horas semanais. Levando em conta que o porcentual de mulheres na docência no ensino básico, segundo essas mesmas pesquisas, tem andado nas últimas décadas em torno de $85 \%$ e que, como o próprio estudo da CNTE afirma, as mulheres professoras, em sua maioria, ocupam-se sozinhas das tarefas domésticas, pode-se ter uma ideia do que significa o prolongamento das jornadas de trabalho a que as entrevistadas por vezes se referem.

Sara, com 23 anos de idade, professora há quatro anos, com habilitação no Curso Normal, modalidade ensino médio, assim fala sobre a intensificação que percebe no seu trabalho:

Eu me sinto uma operária, eu chego no horário da sineta, porque é o que me cabe chegar, eu entro, caio dentro da sala de aula, onde eu estou à frente (...) de 29 crianças, um trabalho muito exaustivo, uma demanda grande, alunos completamente diferentes, uma sala de aula que é um ovo, tu não tem ali uma perspectiva, tu não visualiza construir uma aula diferente em termos de espaço, em termos de público, de tudo... Aí lá vai sineta para hora do recreio. O recreio extremamente limitado pela diretora da escola, então a gente não pode um minuto a mais, um minuto a menos daquele espaço. Então ali é o tempo que a gente tem para comer, para respirar e para comentar de tudo um pouco (...) superficialmente. Então tu volta para a sala de aula, mais tempo. Bate a sineta e tu vai embora para casa. 
Já Heloísa, 35 anos de idade e 16 anos de profissão, com habilitação no Curso Normal, modalidade ensino médio, destaca a desumanização crescente das relações de trabalho e a diminuição da sociabilidade nas escolas:

Então eu acho que a gente está tendo menos espaço, o professor está tendo cada vez menos espaço para dizer o que pensa. Tudo porque o aluno tem que ter 4 horas diárias de aula, não pode ter menos que isso! Só que o professor ter uma hora para se reunir para debater o futuro do aluno isso não é válido? Só é válido aquele tempo que tu está dentro da sala de aula com o aluno? E para eu poder ampliar minha visão de mundo? Eu como ser humano, sociável, eu tenho que conversar, eu tenho que trocar ideias, para eu poder crescer! E não tem esse espaço, a gente não está tendo esse espaço! Para trocar ideias, para poder crescer, para poder debater.

Para Apple (1995), a intensificação do trabalho docente não traz necessariamente a desqualificação das habilidades dos professores e, geralmente, parece implicar a aprendizagem e a reaprendizagem de uma gama de novas habilidades e conhecimentos. As professoras, em seus depoimentos, dizem o quanto foram levadas a desenvolver novas habilidades e conhecimentos no seu processo de trabalho, tanto no ensino como na gestão da escola. Por exemplo, o desenvolvimento de habilidades e conhecimentos implicados no ensino de alunos portadores de necessidades especiais ou na gestão dos recursos financeiros na escola.

As mudanças verificadas no processo de trabalho docente nos últimos anos são vistas pelas professoras entrevistadas, apesar das queixas, como indícios de maior profissionalismo, corroborando a observação da literatura de que quanto mais racionalidade, mais atividades e mais responsabilidades, tanto mais as docentes tendem a se ver como profissionais.

O sentimento de profissionalismo é vinculado ao atendimento pleno de todas as tarefas que vêm se acumulando no processo de trabalho dos professores. Entre os docentes das escolas elementares que atendem crianças dos anos escolares iniciais, o papel do professor engloba finalidades sociais, emocionais, acadêmicas, o zelo para com os pequenos e ainda o desempenho satisfatório na escola (Hargreaves, 1998). Para a maioria das entrevistadas, atender estes diferentes papéis significa a posse de competência profissional. É o que diz Mariana, 33 anos de idade, há 12 no exercício do magistério, que recentemente concluiu o Curso de Licenciatura em Pedagogia: 
E sem contar que além de tudo tu é mãe, tu é tia, tu é vó, quer dizer tu tem que ter um cuidado especial com aquelas crianças, eu mesmo, eu tenho dois deficientes. Tenho um de cadeira de rodas e um que tem um probleminha nas pernas. Então, eu tenho medo quando as crianças vão carregar ele, de deixar cair, de machucar, quer dizer, além de todas as tuas atribuiçôes de professora, tu ainda é um pouquinho mais, tu tem mais responsabilidade. Eu me sinto mais responsável.

A mudança da jornada escolar para quatro horas diárias de atendimento exclusivo aos educandos em sala de aula durante 200 dias letivos e as políticas inclusivas trazidas pelas reformas parecem ter contribuído para a intensificação do trabalho docente. E se isso vem representando um ganho inegável para a educação brasileira, são medidas que desgostam as professoras deste estudo. A impopularidade da extensão do calendário escolar entre os professores é também uma das constatações da pesquisa da UNESCO (2004).

Os depoimentos das professoras revelam o contraditório sentimento de, por um lado, reclamarem do árduo processo de intensificação do fazer docente por meio de queixas frequentes sobre os dilemas que vivenciam na escola e, por outro lado, culpabilizarem-se em função de uma (auto)consciência que as convoca a adquirirem níveis mais altos de responsabilidade profissional e de profissionalização.

A intensificação do trabalho docente pode ter impactos diversos entre os professores e existe uma dificuldade de se comprovar historicamente o fenômeno, dada a falta de estudos sobre o assunto (Hargreaves, 1998). Os sentimentos de cansaço e desânimo dos professores podem estar vinculados ao tempo no exercício do magistério, que acompanharia uma determinada maturidade seguida do declínio de poderes físicos e capacidades reduzidas. No entanto, dado o grau de generalidade que parecem ter esses sentimentos entre os depoimentos aqui analisados, preferiu-se trabalhá-los como sintomáticos das dificuldades que as professoras experimentam e da deterioração crescente das condições do trabalho.

Ao se destacar o sentimento de frustração que por vezes as professoras revelaram em seus depoimentos, não significa que elas abandonariam a profissão, caso pudessem, ou que tenham a intenção de no futuro exercer outra atividade profissional. Parece que os professores brasileiros, apesar de tudo, estão satisfeitos com sua atividade: $63,4 \%$ dos professores entrevistados pela pesquisa da UNESCO (2004) disseram-se 
satisfeitos com sua profissão e 50,2\%, quando perguntados acerca de suas aspiraçōes para um futuro próximo, afirmaram que pretendiam permanecer na mesma função e instituição em que exerciam seu trabalho à altura da pesquisa.

$\mathrm{Na}$ impossibilidade de tirarmos conclusões sobre essa questão no universo pesquisado, é importante notarmos que as entrevistadas são professoras de séries iniciais, que trabalham em escolas municipais (que de modo geral paga os salários mais baixos) de um pequeno município com características rurais, condições que já as colocam numa posição a mais desfavorável, do ponto de vista estatístico, em um continuum de condições que por si são difíceis para o conjunto da categoria de professores do ensino básico brasileiro.

As estratégias de estímulo à autointensificação e a colonização administrativa das emoçóes no ensino

Os aspectos da autointensificação do trabalho e da colonização administrativa das emoções das professoras no ensino, que se quer demonstrar nesta seção, dizem respeito à exploração, pelos discursos e pelas propostas educacionais oficiais, das autoimagens e dos sentimentos de profissionalismo das professoras. Isso acontece tanto pela incitação a sentimentos de autorresponsabilização das professoras pelo fracasso da escola pública como pelo estímulo ao engajamento em mecanismos de profissionalização e ao exercício de uma conduta profissional baseada em uma ética salvacionista e missionária. A base necessária da intensificação do trabalho docente é o consentimento voluntário dos professores nesse processo.

Nas democracias liberais avançadas, destaca Rose (1996), a psique humana tornou-se um campo possível para o governo sistemático, de modo a atingirem-se fins sociopolíticos. As estratégias de governo da psique ou de governo do eu agem sobretudo por meio da persuasão de suas verdades, das ansiedades criadas pelas suas normas e pela atração das imagens de vida, de sucesso e de felicidade que oferecem. $\mathrm{O}$ apelo à profissionalização docente e ao exercício de certo profissionalismo com que os docentes vêm sendo interpelados nas últimas décadas, implicando as suas autoimagens e os seus sentimentos, são aspectos que têm contribuído para os processos de autointensificação do trabalho docente. 
Autores como Rose (1996) e outros como Peters, Marshall e Fitzsimons (2004), e, entre nós, Veiga-Neto (2000), destacam o interesse da noção foucaultiana de governamentalidade (Foucault, 1979) para explicar as racionalidades de governo que interconectam as tecnologias de poder sobre os outros com as tecnologias do eu (ou práticas de si), em regimes cuja racionalidade política está baseada no liberalismo, incluindo as versōes do neoliberalismo que sustentam atualmente pelo globo várias políticas nacionais. Sob muitos pontos de vista, o neoliberalismo vem fundamentando as políticas dos governos brasileiros desde a eleição do presidente Fernando Collor de Melo, em 1989 , instituindo racionalidades de governo que estimulam novas formas de gerencialismo e autogerencialismo que supõem a participação ativa dos professores em sua própria sujeição.

Ball $(2001,2005)$, a partir da experiência inglesa, destaca a ascensão do discurso gerencialista nas políticas educacionais como uma das tendências globalizantes dessas políticas, mesmo ressaltando a importância das características locais nas políticas educacionais, que são o resultado de negociações e recontextualizaçôes entre interesses e teorias por vezes antagônicos. Os discursos das políticas educacionais são híbridos de interesses e soluções suficientemente vagos para permitirem um conjunto mais ou menos extenso de respostas possíveis. O novo gerencialismo faz-se acompanhar de uma forte cobrança em torno da performatividade, uma política de resultados centrada em desempenhos quantificáveis. Uma tendência que no Brasil, pelo menos comparando com as formas mais acabadas que ele descreve, tem sua manifestação no sistema oficial de avaliação da pós-graduação brasileira.

Contudo, talvez se pudesse pensar em o quanto essa observação vale para entender as estratégias que têm buscado conduzir as atitudes de professoras e professores da educação básica em relação ao seu trabalho. A responsabilização moral das professoras por suas ocupações e pelo êxito da escola, a ênfase tão pronunciada no seu comportamento, em suas performances e desempenhos na escola, como se delas dependesse fortemente o sucesso ou o fracasso da escola, podem ser vistos como uma forma de gerencialismo. $\mathrm{O}$ discurso do profissionalismo e a incitação à profissionalização são estratégias importantes de governo do trabalho e da identidade docentes no bojo das políticas educacionais em curso no Brasil. 
Das oito professoras entrevistadas, quatro possuem formação em nível de ensino médio, habilitação para Magistério, e quatro, além dessa habilitação, possuem ainda o curso de licenciatura plena em Pedagogia, habilitação para o Magistério dos anos iniciais do ensino fundamental, sendo que, dessas, três professoras tinham-se titulado recentemente em Pedagogia por intermédio de cursos ofertados por Programas Especiais de Formação de Professores em Serviço. Metade do grupo de oito professoras entrevistadas tem ainda cursos de pós-graduação em Educação, em nível de Especialização, ou estava frequentando algum curso desse nível quando da coleta dos depoimentos. De modo geral, as professoras reconheceram em seus depoimentos o forte estímulo que tiveram dos discursos e das políticas oficiais em ampliar seus níveis de profissionalização nos últimos anos, indicando a importância desses cursos no alargamento de suas perspectivas e na construção de suas competências profissionais, apesar de muitas vezes essa exigência ter representado, para algumas delas, um ônus a mais nas suas vidas. Algumas acrescentaram ainda que essas políticas ampliaram os níveis de competição na categoria docente, pois ter um título de nível superior passou a ser um forte critério de diferenciação interna na categoria docente.

Exemplar dos efeitos dos apelos ao profissionalismo e à profissionalização docente são os sentimentos e as autoimagens das docentes entrevistadas que não tiveram condições de investir na própria carreira profissional. Tanto para Aline, que cursou o ensino médio com habilitação para o Magistério nos anos de 1990, quanto para Irene, que cursou igual modalidade nos anos de 1980, não ter feito um curso de licenciatura é motivo de vergonha e culpa, considerando as novas exigências de profissionalização e o movimento que elas observam das colegas a fim de atenderem a essa exigência. Diz Aline:

Se foi uma década de educação, eu estou me sentindo duas décadas de educação atrás! Estou me sentindo assim muito pra trás! Muito parada no tempo! Eu me formei em 98! A maioria das minhas colegas, se não estão fazendo faculdade, já se formaram. Daquele mesmo ano que se formaram comigo! Então estou me sentindo assim um zero à esquerda. Eu não sou a única.

E Irene:

Só que hoje em dia eu gostaria de fazer. (...) eu acho que assim eu estou ficando tão pra trás, tão pra trás, tão pra trás, tradicional, pra trás nas 
ideias. Eu vejo pelo grupo de colegas, todas estão fazendo, então é uma coisa que eu gostaria de fazer bastante. (...) Mas eu acho que eu estou vendo a coisa pra esse ponto (risos), porque diz que vai abrir uma nova turma então vou ter que fazer alguma coisa por mim, porque agora é por $\mathrm{mim}$. Antes eu acho que eu não fiz por causa dos filhos, eu abri mão por causa dos filhos, eu abri mão por causa da mãe, abri mão de tudo. Hoje eu quero me modernizar um pouco (...). Eu ainda continuo tradicional no meu trabalho, eu acho que eu tenho mudanças a fazer.

Pode-se pensar que Irene, com 22 anos de magistério e, portanto, em final de carreira, tem razões suficientes para sentir-se desanimada e frustrada por não ter investido em um curso de licenciatura, porém Aline está em início de carreira e formou-se recentemente, no entanto sente-se igualmente culpada e defasada no seu perfil profissional.

$\mathrm{O}$ conceito de profissionalismo docente predominante nos meios acadêmicos é fortemente vinculado a uma visão androcêntrica. Tem sido estratégia do campo educacional e dos cursos de formação de professores o estímulo a uma concepção de docência assentada em características como a objetividade, a cientificidade, a ênfase nos aspectos instrucionais, e em dicotomias como a rígida separação entre o profissional e o doméstico, entre a razão e o afeto, entre o público e o privado, entre o racional, a intuição e o improviso. Sendo o primeiro pólo dessas dicotomias aspectos construídos historicamente como pertencendo ao jeito de ser dos homens, e, portanto, mais valorizados no mundo das ocupaçóes remuneradas. As características culturalmente atribuídas ao gênero feminino, como a sensibilidade, a afetividade, a paciência, a atenção ao detalhe, o improviso, foram e continuam sendo sinônimos de sentimentalismo, domesticidade e pouco profissionalismo, aspectos condenáveis ou pouco promissores na conquista de maior autoridade científica para a pedagogia e de melhores condições profissionais para o exercício da docência (Louro, 1997; Carvalho, 1999).

As professoras, em certa medida, são aprisionadas por esses discursos e imagens, e interpeladas por discursos e demandas acerca de suas atribuições que reforçam uma ética salvacionista e missionária em relação à educação. Aos discursos oficiais, que desde os anos da década de 1990 vieram atribuindo a culpa do fracasso escolar aos professores, vieram se somar as cobranças de outros setores sociais.

Quando as professoras foram levadas a falar sobre o seu cotidiano escolar, destacaram aspectos da função social da escola que sempre 
estiveram no cerne das funções docentes na educação elementar da infância, mas que hoje parecem ser especialmente lembradas diante do recrudescimento dos problemas de ordem social e econômica e do esgarçamento dos laços sociais e familiares. "Não nos cobravam tanto assim", diz Ester, professora dos anos iniciais há 15 anos, ressaltando as responsabilidades que a comunidade e a sociedade cobram dos professores, mesmo não estando muito confiantes sobre a autoridade e a eficiência da escola e dos professores na socialização das novas gerações. As complexidades da vida moderna e a ampliação das dificuldades econômicas para setores cada vez mais amplos da sociedade imprimiram um ritmo cada vez mais veloz à vida contemporânea, fazendo com que a escola seja chamada a substituir em grande parte os papéis da família na guarda e na educação das crianças.

Também Sara, 23 anos de idade, há apenas quatro anos na docência dos anos iniciais, fala de uma confluência de demandas provenientes de diferentes lugares que chegam ao seu trabalho:

A comunidade, os pais. Eles entendem que quando (...) eles colocam o filho na escola eles acham que é para tudo. Para a gente formar uma criança, e tem até colegas acadêmicas que acham que a gente vai fazer isso, que a gente vai transformar, que a gente vai formar um cidadão. Então às vezes colocam no professor mais que a tarefa com o conhecimento. Então a gente está tendo que trabalhar a questão comportamental, a questão de atitudes, questão de posições, as novas demandas da atualidade. (...).

O discurso educacional oficial tem utilizado esse sentimento em relação à escola para minar a já desacreditada autoridade docente e conclamar a sociedade a corresponsabilizar-se com o Estado na implementação, na manutenção e na fiscalização das políticas educacionais. A comunidade e a sociedade têm sido chamadas a serem "amigas" da escola, a adotar as escolas e os alunos, enfim, a participar da gestão e da fiscalização da instituição escolar. $\mathrm{O}$ que certamente tornou os professores sujeitos a maiores avaliações e críticas por parte de setores da sociedade, contribuindo para a elevação das exigências de ordem moral e profissional.

Esse empreendimento discursivo, por vezes contraditório, que busca gerenciar as professoras de dentro para fora, vem se fortalecendo a partir de uma tradição social que construiu o magistério dos anos iniciais como um espaço de atuação de mulheres, cujas características se identificam com as necessidades da faixa etária da modalidade de ensino 
em questão. $\mathrm{O}$ magistério historicamente foi um dos primeiros espaços públicos de atuação profissional permitido às mulheres e, à medida que elas foram ocupando a maioria desses postos de trabalho, essa ocupação também foi sendo associada a peculiaridades culturais próprias do feminino, de tal modo que hoje é comum a representação social de que as mulheres teriam inclinações naturais para se encarregar da escolarização inicial da infância.

Essa é uma ideia que é reiteradamente atualizada nas autoimagens das professoras entrevistadas. Quando levadas a definirem o seu papel junto dos alunos, enfatizaram aspectos da educação relacionados ao disciplinamento da conduta, ao cuidado e ao zelo, não dissociando as funções instrucionais das funções formativas e afetivas na educação da infância.

Os vínculos entre a maternidade, a domesticidade e a docência nesse nível de ensino são uma constante nos depoimentos das entrevistadas. Irene é um dos exemplos:

É eu me coloco assim, por ser mãe, por ter filhos, a gente entende as crianças às vezes com problemas dentro da sala de aula. Não vou dizer que quem não é mãe não entenda também, mas é um vínculo mais materno. (....), me coloco assim como mãe e como professora ao mesmo tempo. Em casa eu sou mãe e sou professora, na escola eu também sou professora e também sou mãe. Porque as coisas me comovem, as coisas me chocam, eu às vezes fico com pena (...). Eu às vezes na escola não lido com a criança como um aluno, eu acho que poderia ser meu filho. Porque se eu avaliar eu tenho filhos de tudo o que é idade. Então, todos os que estão na sala de aula todos poderiam ser (...) às vezes as coisas acontecem assim.

É o que também diz Carmen, 37 anos de idade e há 18 no magistério, quando avalia as mudanças dos últimos anos nas condições do seu trabalho:

Eu acho assim, tu tem novas preocupações, tu vai para casa, tu fica pensando sobre aquilo, tu deita no teu travesseirinho, e aí tu fica ali, pensando, pensando no que tu pode melhorar. Nessa parte, eu acho, são mais atribuições para nós. Mas eu acho que é muito bom! Porque é bom tu participar daquilo que tu estás trabalhando, é o teu ambiente. É tu fazer a coisa com vontade realmente de melhorar. Não é só chegar, despejar o teu conteúdo, dar a tua aula, ir embora e não ter vínculo nenhum com a escola. Eu pelo menos aqui... Bom, eu sempre fui assim, e cada vez sou mais, 
trabalho agora 40 horas aqui na mesma escola. Então aqui é minha família também. Eu me preocupo tanto quanto lá em casa. Então, são mais atribuiçōes? É, está. Mas por um lado eu acho que vale a pena.

O cuidado parece ocupar um lugar central na ética e na organização do trabalho docente na escola elementar. Como diz Hargreaves (1998), o cuidado pode ter múltiplos sentidos para diferentes sujeitos ou profissionais, como pode ter também diferentes gradientes envolvendo mais ou menos as vidas dos professores e das professoras. Para as entrevistadas, o cuidado no trabalho é definido preponderantemente por princípios de calor humano, de afeto, de atenção e zelo pelos outros, mais que por princípios relacionados à eficácia na aprendizagem ou ao processo de instrução. Isso parece levar as professoras de nosso estudo a constantes associações entre as funções maternas e profissionais, pois as responsabilidades e o empenho no trabalho são, para muitas, equivalentes às responsabilidades domésticas e maternas.

Por vezes as professoras, em suas falas, parecem colocar-se no interior de discursos sobre o profissionalismo docente que enfatizam termos dos discursos vigentes sobre esse tema nos cursos de formação profissional no ensino superior e no campo acadêmico. Vale lembrar que, do grupo das oito professoras entrevistadas, a metade tem curso de licenciatura em Pedagogia e já concluiu ou estava cursando, à época da coleta de dados, cursos de especialização na área de educação. Porém esses discursos não são muito enfáticos, nem parecem possuir a dose de envolvimento pessoal que emerge quando elas definem suas ocupações profissionais por aproximações com representaçôes típicas da maternidade, das profissōes que envolvem formas de cuidado (psicólogas, médicas, enfermeiras) e do que, talvez, pudéssemos chamar da domesticidade.

As professoras, ao se descreverem, ao narrarem seu dia-a-dia, indicam a complexidade do seu cotidiano pela exigência de atenderem a um número cada vez maior de atribuições dentro do espaço doméstico e público em que atuam. Diante das mudanças tecnológicas, sociais, culturais e políticas, as professoras encontram muitas vantagens, muitas melhorias em termos de serem reconhecidas como cidadãs de direitos, de conquistarem espaços antes restritos aos homens, enfim, de terem vez e voz em diferentes esferas da prática social e política. No entanto, a entrada das mulheres no universo público não 
foi acompanhada, na mesma medida, por uma participação mais igualitária dos homens nas demandas do mundo doméstico. O que fica evidenciado nos relatos das professoras é o acúmulo de trabalho e de tarefas advindas da vida profissional e doméstica, dois universos que se cruzam e interconectam, construindo identidades profissionais e autoimagens atravessadas pelas características da maternidade e das atividades domésticas.

\section{Conclusão}

Muitas das expectativas e das rigorosas exigências colocadas à docência parecem também ser feitas pelas próprias professoras. As estratégias de intensificação do trabalho docente em curso nas reformas da década de 1990 parecem, sim, incluir a ampliação das tarefas a serem desempenhadas pelas professoras no cotidiano das escolas, mas também a colonização ou o governo de seus sentimentos em relação ao seu trabalho e às suas carreiras, envolvendo os espaços privados e domésticos, seus tempos de descanso e suas energias. Há, por parte das docentes, um esforço adicional em termos de autorresponsabilização e autoempreendedorismo no trabalho e na carreira, o que demanda tempo e outros investimentos.

Argumentou-se que as racionalidades de governo, no bojo das reformas educacionais que tiveram como palco o neoliberalismo e os anos de 1990 no Brasil, elegeram como alvo de sua retórica, entre outros aspectos, as emoções e a subjetividade das professoras, a fim de instituírem certos ordenamentos nos currículos e no ensino e de buscar a aquiescência e o engajamento dos professores com as reformas dessa década.

O governo da alma e da conduta humana nos tempos modernos elege como objetivos administrativos aspiraçôes e sentimentos que temos por mais privados, como os desejos de sucesso, de competência e de solidariedade (Rose, 1996). A retórica de exaltação do mercado conclama os indivíduos a tomarem para si a responsabilidade por suas vitórias e fracassos e a dividir com o poder público a gestão dos problemas sociais, enfraquecendo argumentos e aspectos de ordem econômica, social e cultural e da participação do próprio Estado na vida social. O discurso do profissionalismo docente joga um papel decisivo nas novas formas de intensificação e controle do trabalho docente. 
A intensificação é apoiada voluntariamente pelas professoras entrevistadas e confundida com maior profissionalismo, sentimento que é estrategicamente mobilizado pelas exigências oficiais de profissionalização docente e pelo apelo a uma ética de autorresponsabilização moral e individual pelo sucesso da escola. Essas formas de gestão da conduta deslocaram e ao mesmo tempo se combinam, pelo menos no nosso estudo, com formas mais tradicionais de controle do trabalho docente, como a supervisão direta no próprio local de trabalho e a demanda por trabalho burocrático para prestação de contas do ensino.

A sedução levada a efeito por discursos que apelam ao profissionalismo combina-se com o estímulo a uma ética pastoral (Garcia, 2002) e ao autogerencialismo, que exalta as virtudes das professoras no cuidado das crianças e no sucesso da escola, apelos que encontram território fértil nas qualidades atribuídas ao gênero feminino e na história das mulheres no cuidado da família, da casa e da infância. As autoimagens e os sentimentos que as professoras têm em relação à natureza de suas atribuições na educação infantil, bem como as características e condiçóes desiguais de existência do gênero feminino em nossas sociedades, fazem parte do amálgama de discursos, afetos e medidas que colaboram para o processo de intensificação e autointensificação do trabalho docente.

Recebido em fevereiro de 2008 e aprovado em maio de 2008.

\section{Notas}

1. Como a pesquisa privilegiou relatos de natureza biográfica, optou-se por trabalhar com um pequeno número de professoras, escolhidas conforme os critérios: a) diferentes tempos de exercício no magistério: início, metade e em fim de carreira; b) diferentes habilitaçōes para o magistério de $1^{\text {a }}$ a 4 série: nível médio, licenciatura, pós-graduação; c) interesse e disponibilidade para participar da pesquisa. Os nomes com que as professoras são identificadas no decorrer deste texto são fictícios.

2. Capão do Leão, típica cidade do interior da zona sul do Rio Grande do Sul, possui cerca de 25.337 habitantes e caracteriza-se basicamente pela presença de grandes latifúndios. Sua economia é baseada principalmente na atividade agropecuária e na extração de granito.

3. Entre o $2^{\circ}$ semestre de 1998 e o $2^{\circ}$ semestre de 2005, portanto em sete anos, o Programa Especial de Formação de Professores em Serviço nas Redes de Ensino da Região Sul do Estado do RS, desenvolvido pela Faculdade de Educação da Universidade Federal de Pelotas, em parceria com as prefeituras dos municípios de Arroio Grande, Jaguarão, São Lourenço do Sul, Pelotas, Capão do Leão e Turuçu, titulou 792 professores com habilitação para o

Educ. Soc., Campinas, vol. 30, n. 106, p. 63-85, jan./abr. 2009 
Reforma educacional, intensificação e autointensificação do trabalho docente

magistério nos anos iniciais da educação básica. A proliferação da maioria desses programas nas últimas décadas teve como motivação principal a exigência da LDB n. 9.394/96 de habilitação de nível superior para o magistério nos anos iniciais.

\section{Referências}

ANADON, S.B. Trabalho e identidade docente no contexto da reforma educacional iniciada na década de 1990. 2005. 160f. Dissertação (Mestrado) - Faculdade de Educação, Universidade Federal de Pelotas, Pelotas.

APPLE, M. Trabalho docente e textos: economia política das relações de classe e gênero. Porto Alegre: Artes Médicas, 1995.

BALL, S. Diretrizes políticas globais e relações políticas locais em educação. Currículo sem Fronteiras, v. 1, n. 2, p. 99-116, jul./dez. 2001. Disponível em: <http://www.curriculosemfronteiras.org>. Acesso em: 15 dez. 2005.

BALL, S. Profissionalismo, gerencialismo e performatividade. Cadernos de Pesquisa, São Paulo, v. 35, n. 126, p. 539-564, set./dez. 2005.

BRASIL. Ministério da Educação. Instituto Nacional de Estudos e Pesquisas Educacionais (INEP). Censo do professor 1997: perfil dos docentes da educação básica. Brasília, DF: INEP, 1999.

BRASIL. Ministério da Educação. Instituto Nacional de Estudos e Pesquisas Educacionais (INEP). Sinopse do censo dos profissionais do magistério da educação básica: 2003. Brasília, DF: INEP, 2006.

CARVALHO, M.P. No coração da sala de aula: gênero e trabalho docente nas séries iniciais. São Paulo: Xamã, 1999.

CONFEDERAÇÃO NACIONAL DOS TRABALHADORES EM EDUCAÇÃO (CNTE). Relatório de Pesquisa sobre a situação dos trabalhadores(as) da educação básica. Brasília, DF: CNTE /DIEESE, 2003. (Retrato da Escola, 3).

CUNHA, L.A. Movimentos sociais, sindicais e acadêmicos. In: CUNHA, L.A. Educação, Estado e democracia no Brasil. São Paulo: Cortez; Niterói: UfF; Brasília, DF: FLACSO do Brasil, 1991. p. 60-101. 
FERREIRA JR., A.; BITTAR, M. A ditadura militar e a proletarização dos professores. Educação \& Sociedade, Campinas, v. 27, n. 97, p. 1159-1179, set./dez. 2006.

FOUCAULT, M. A governamentalidade. In: Foucault, M. Microfísica do poder. 9. ed. Rio de Janeiro: Graal, 1979. p. 277-293.

GARCIA, M.M.A. Pedagogias criticas e subjetivação: uma perspectiva foucaultiana. Petrópolis: Vozes, 2002.

HARGREAVES, A. Os professores em tempos de mudanças: o trabalho e a cultura dos professores na Idade Moderna. Lisboa: McGraw-Hill, 1998.

LOURO, G.L. Gênero, sexualidade e educação: uma perspectiva pósestruturalista. Petrópolis: Vozes, 1997.

OLIVEIRA, D. A reestruturação do trabalho docente: precarização e flexibilização. Educação \& Sociedade, Campinas, v. 25, n. 89, p. 1127-1144, set./dez. 2004.

PETERS, M.; MARSHALL, J.; FITZSIMONS, P. Gerencialismo e política educacional em um contexto global: Foucault, neoliberalismo e a doutrina da auto-administração. In: Burbules, N.C.; Torres, C.A. Globalização e educação: perspectivas críticas. Porto Alegre: ARTMED, 2004. p. 77-90.

ROSE, N. Inventing our selves: psychology, power, and personhood. Austrália: Cambridge University, 1996.

SAMPAIO, M.; MARIN, A. Precarização do trabalho docente e seus efeitos sobre as práticas curriculares. Educação \& Sociedade, Campinas, v. 25, n. 89, p. 1203-1225, set./dez. 2004.

UNESCO. O perfil do professor brasileiro: o que fazem, o que pensam, o que almejam. São Paulo: Moderna, 2004.

VEIGA-NETO, A. Educação e governamentalidade neoliberal: novos dispositivos, novas subjetividades. In: Portocarrero, V.; Branco, G.C. (Org.). Retratos de Foucault. Rio de Janeiro: Nau, 2000. p. 179-217. 